\title{
Tumor Necrosis Factor, Interleukin 6, and the Acute Phase Response Following Hepatic Ischemia/Reperfusion'
}

\author{
Kenneth R. McCurry, M.D., ${ }^{*}$ Darrell A. Campbell, JR., M.D., ${ }^{* 2}$ Wendy E. Scales, Ph.D.,* \\ JefFrey S. WarRen, M.D., $\dagger$ AND DANIEL G. REMICK, M.D. $\dagger$ \\ Departments of *Surgery and $\uparrow$ Pathology, University of Michigan Medical Center, Ann Arbor, Michigan 48109
}

Submitted for publication November 27, 1991

\begin{abstract}
We report here the production of systemic levels of tumor necrosis factor (TNF) and interleukin 6 (IL-6) and associated changes in serum macroglobulin to albumin ratios in a nonlethal rat model of partial hepatic ischemia/reperfusion (I/R). Plasma IL-6 was detectable and elevated at $1 \mathrm{hr}$ of reperfusion as compared to sham-operated controls ( $/ \mathrm{R}$ rats $=12,100 \pm 3860 \mathrm{pg}$ ) $\mathrm{ml}$; sham rats $=\mathbf{5 2 6 0} \pm 842 \mathrm{pg} / \mathrm{ml}$; IL-6 values $=$ means \pm SEM) and reached maximal levels at $6 \mathrm{hr}$ of reperfusion $(I / R$ rats $=47,400 \pm 25,700 \mathrm{pg} / \mathrm{ml}$; sham rats $=$ $3370 \pm 394 \mathrm{pg} / \mathrm{ml}$ ), in contrast to maximal TNF levels at $30 \mathrm{~min}$ of reperfusion (I/R rats $=72 \pm 15 \mathrm{pg} / \mathrm{ml}$; $\mathrm{sham}$ rats $=2 \pm 2 \mathrm{pg} / \mathrm{ml}$; TNF values $=$ means \pm SEM). Pretreatment with neutralizing TNF antisera prior to ischemia resulted in a reduction of $\mathrm{IL}-6$ at $1 \mathrm{hr}$ of reperfusion (anti-TNF $=\mathbf{3 8 7 0} \pm \mathbf{2 5 5 0} \mathrm{pg} / \mathrm{ml}$; control serum $=$ $7650 \pm 1670 \mathrm{pg} / \mathrm{ml}$ ), but was without effect on IL-6 levels at subsequent time points over the $24 \mathrm{hr}$ of reperfusion. Electrophoretic determination of macroglobulin $\left(\alpha_{1}+\alpha_{2}\right)$ and albumin concentrations in sham-operated and ischemia/reperfusion animals demonstrated an elevation in the macroglobulin/albumin ratio in both groups over time, suggestive of an acute phase response, and the ratio was unchanged by immunoneutralization of TNF prior to ischemia/reperfusion. We conclude that this model of hepatic ischemia/reperfusion results in temporally distinct systemic elevations in IL-6 and TNF; however, the induction of IL-6 and the associated changes in serum macroglobulin concentration are independent of TNF. @ 1993 Academic Press, Inc.
\end{abstract}

\section{INTRODUCTION}

Interleukin 6 (IL-6) has diverse biological functions, including the ability to induce immunoglobulin production in proliferating $B$ cells [1], to enhance the development of multipotential hemopoietic progenitor cells [2], and to participate in the development of cytotoxic $\mathrm{T}$ cells [3]. Apart from effects which serve to upregulate

\footnotetext{
${ }^{1}$ Presented at the Annual Meeting of the Association for Academic Surgery, Colorado Springs, CO, November 20-23, 1991.

2 To whom correspondence should be addressed at the University of Michigan Medical Center, 2920 Taubman Center, 1500 E. Medical Center Drive, Ann Arbor, MI 48109-0331.
}

immune responsiveness, IL-6 is increasingly recognized as a nearly ubiquitous participant in many types of inflammatory processes. Most importantly, IL-6 is a powerful inducer of acute phase reactants by hepatocytes [4]. Acute phase proteins such as $\alpha_{2}$-macroglobulin, $\alpha_{1}$ proteinase inhibitor, and $\alpha_{1}$-antichymotrypsin are thought to limit inflammatory reactions by virtue of antiproteinase activity [5]. We have previously demonstrated that tumor necrosis factor (TNF) is intimately involved in the pathophysiologic alterations following hepatic ischemia/reperfusion $(\mathrm{I} / \mathrm{R})$ in the rat $[6,7]$. of particular interest to us was the observation that TNF appeared in plasma for brief periods following hepatic ischemia/reperfusion, and that pretreatment with neutralizing antibody to TNF would protect against postreperfusion hepatic and pulmonary injury. Since IL-6 production can be stimulated by TNF [8], we hypothesized that IL- 6 may be produced in response to hepatic ischemia/reperfusion in this model. Such a response may be particularly relevant, as the stimulation of IL-6 and subsequent elevation in acute phase proteins in response to hepatic ischemia/reperfusion may function to limit hepatocellular injury due to the antiproteinase properties inherent to many acute phase proteins. In this communication, we have examined the relationship between TNF and IL-6 production following $2 \mathrm{hr}$ of partial hepatic ischemia with subsequent reperfusion in the rat, and measured serum concentrations of macroglobulin $\left(\alpha_{1}+\right.$ $\alpha_{2}$ ) and albumin as indices of an acute phase response.

\section{MATERIALS AND METHODS}

Animal model. Adult, male, pathogen-free SpragueDawley rats (Charles River Breeding Laboratories, Inc., Portage, MI) weighing 275-300 g were fasted overnight with free access to water. On the following morning, animals were anesthetized with inhalation methoxyflurane and intramuscular ketamine $(100 \mathrm{mg} / \mathrm{kg}$ body wt). Following a midline laparotomy the portal triad was exposed and a vascular clip applied cephalad to the branches of the right and caudate lobes, thus occluding the portal vein, hepatic artery, and bile duct to the median and left lobes (approximately $70 \%$ of the mass of 
the liver). This method of partial hepatic ischemia/reperfusion allows for portal decompression through the right and caudate lobes and thus prevents mesenteric venous congestion [9]. The abdomen was then closed in a single layer and following $2 \mathrm{hr}$ of ischemia the clip was removed at a second laparotomy. Following reperfusion the abdomen was closed. Animals received $0.75 \mathrm{ml}$ of lactated Ringer's solution subcutaneously to replace operative blood losses as well as $1 \mathrm{ml}$ at $1 \mathrm{hr}$ of ischemia and $2 \mathrm{ml}$ at $1 \mathrm{hr}$ of reperfusion to ensure adequate hydration. Animals were allowed free access to water after awakening from anesthesia. Sham animals were treated in an identical fashion with omission of vascular occlusion. In contrast to our previous work $[6,7]$, the model now consists of $2 \mathrm{hr}$ of ischemia in nonheparinized rats as compared to $90 \mathrm{~min}$ of ischemia in heparinized rats.

In selected experiments, as outlined below, an intravenous catheter was inserted for sequential blood draws. Following initiation of anesthesia, the catheter $(0.04$ in. i.d., 0.07 in. e.d.) was inserted into the right internal jugular vein through a cutdown. The catheter was advanced into the suprahepatic vena cava and secured in place. Blood draws were then performed at the intervals outlined below.

TNF and IL-6 kinetics. Indwelling catheters were placed as described above. Five study group animals and four sham-operated animals then underwent $I / R$ or sham operation. Blood was drawn $(0.3 \mathrm{ml} /$ blood draw $)$ for determination of TNF and IL-6 levels with heparinized syringes. Blood was obtained prior to the first laparotomy, at $2 \mathrm{hr}$ of ischemia (prior to reperfusion), and at $30,60,90,120$, and $180 \mathrm{~min}$ of reperfusion. To assess the effect of longer reperfusion times on IL-6 levels, a $24-\mathrm{hr}$ kinetic analysis was performed. In this set of experiments, animals underwent either I/R or sham operation following which blood was obtained only at the time of sacrifice. Animals were sacrificed at $2 \mathrm{hr}$ of ischemia (without reperfusion) and at $1,3,6,12$, and $24 \mathrm{hr}$ of reperfusion. Six animals were utilized in each $\mathrm{I} / \mathrm{R}$ group and four in each sham group.

IL-6 kinetics following pretreatment with anti-TNF antiserum. To assess the effect of TNF on IL-6 levels, animals were pretreated with a polyclonal rabbit antimurine TNF antiserum that cross-reacts with rat TNF $[10,11]$. This antiserum neutralizes TNF and has no cross-reactivity with interleukin 1 or LPS. One milliliter of antiserum or $1 \mathrm{ml}$ of control rabbit serum was diluted 1:10 and given via an indwelling venous catheter just prior to the initiation of hepatic ischemia. Animals then underwent I/R and groups were sacrificed at $2 \mathrm{hr}$ of ischemia (prior to reperfusion) and at 1, 3, 6, and $24 \mathrm{hr}$ of reperfusion. Blood was obtained with heparinized syringes at the time of sacrifice for determination of plasma IL-6 levels. There were five animals in each I/R group and four in each sham-operated group.

Acute phase response. Four groups of animals were utilized: (1) sham operation ( $n=9)$, (2) I/R without pre- treatment $(n=7)$, (3) I/R with anti-TNF antiserum pretreatment ( $n=5)$, and (4) I/R with control serum pretreatment $(n=6)$. Animals were pretreated immediately prior to the onset of hepatic ischemia, as described above. Blood was obtained from an indwelling line prior to the onset of hepatic ischemia and at 6 and $24 \mathrm{hr}$ of reperfusion. Serum was separated from cells via centrifugation and the samples were frozen until assayed. Serum protein electrophoresis was performed by the clinical immunopathology laboratory at our institution. Macroglobulin $\left(\alpha_{1}+\alpha_{2}\right)$ and albumin levels were expressed as the fraction of the total protein. The data are expressed as a ratio by the formula

$$
\frac{\text { macroglobulin }}{\text { albumin }}=\frac{\alpha_{1}+\alpha_{2} \text { macroglobulin percentage }}{\text { albumin percentage }} .
$$

The change in ratio of macroglobulin to albumin was used as an indicator of acute phase reactant production. An elevation in the above ratio (due to an increase in macroglobulin and/or reduction in albumin concentration) is suggestive of an acute phase response.

TNF assay. Plasma TNF bioactivity was measured as previously described using the WEHI 164 subclone 13 cell line [12]. Serial dilutions of human recombinant TNF were used to generate a standard curve for each assay. TNF values in experimental samples were calculated utilizing the standard curve.

$I L-6$ assay. Plasma IL- 6 bioactivity was measured using the IL-6-dependent mouse hybridoma cell line clone B9, as previously described [13]. Serial dilutions of human recombinant IL-6 (Peprotech, Rocky Hill, NJ) were used to generate a standard curve for each assay. IL-6 values in experimental samples were calculated utilizing the standard curve.

Statistics. Groups were compared using the Kruskal-Wallis test. If there was a significant difference, then the groups were compared at each time point using Student's $t$ test (i.e., IL-6 in sham vs I/R at $180 \mathrm{~min}$ ). Significance was accepted at $P \leqslant 0.05$. Data are expressed as means \pm SEM.

\section{RESULTS}

Consistent with our previous model using heparinized rats, $2 \mathrm{hr}$ of partial hepatic ischemia followed by reperfusion resulted in a dramatic rise in plasma TNF, reaching maximal levels at $30 \mathrm{~min}$ of reperfusion, with declining but still significant levels at $3 \mathrm{hr}$ of reperfusion (Fig. 1). Prelaparotomy plasma TNF levels were low in both sham and IR groups, with minimal TNF levels detected in the plasma of sham-operated animals over the time course of the experiment. The kinetics of IL-6 appearance in the plasma are shown in Fig. 2. Low levels of biologically active IL- 6 were detectable in both groups prior to the initial laparotomy, increasing to $893 \pm 65$ 


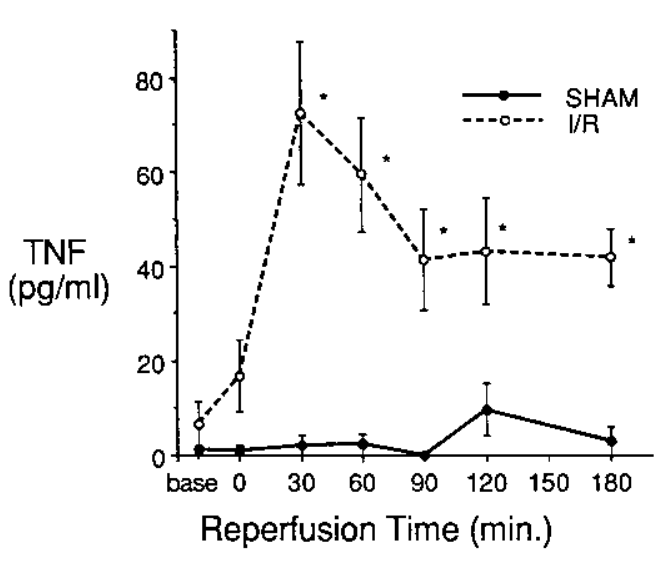

FIG. 1. Plasma levels of TNF following hepatic ischemia/reperfusion. Base represents the preischemic plasma TNF values, while Time 0 indicates the values at $2 \mathrm{hr}$ of hepatic ischemia (prior to reperfusion). SHAM represents animals undergoing laparotomy with omis. sion of vascular occlusion; I/R represents animals undergoing $2 \mathrm{hr}$ of hepatic ischemia followed by reperfusion. Values $=$ means $\pm \mathrm{SEM}, n$ $=5 \mathrm{I} / \mathrm{R}$ rats, $n=4$ sham rats. ${ }^{*} P \leqslant 0.05$ compared to sham values at similar time points.

$\mathrm{pg} / \mathrm{ml}$ and $2740 \pm 1040 \mathrm{pg} / \mathrm{ml}$ in the sham and ischemic animals, respectively, at the end of the $2-\mathrm{hr}$ ischemic interval. As seen in Fig. 2, a dramatic elevation in plasma IL-6 occurred at 60 through $180 \mathrm{~min}$ of reperfusion in the I/R group of rats, while minimal IL-6 levels were noted over this time course in the sham-operated controls, confirming our hypothesis that IL- 6 would be produced as a result of hepatic ischemia/reperfusion. A kinetic comparison of plasma TNF (Fig. 1) and IL-6 (Fig. 2) following ischemia/reperfusion clearly shows the more rapid induction of TNF compared to that of IL-6 in this model. In an effort to better evaluate the kinetic profile of IL- 6 production following hepatic ischemia/reperfusion, we measured biologically active IL-6 in the plasma over $24 \mathrm{hr}$ of reperfusion (Fig. 3). Although

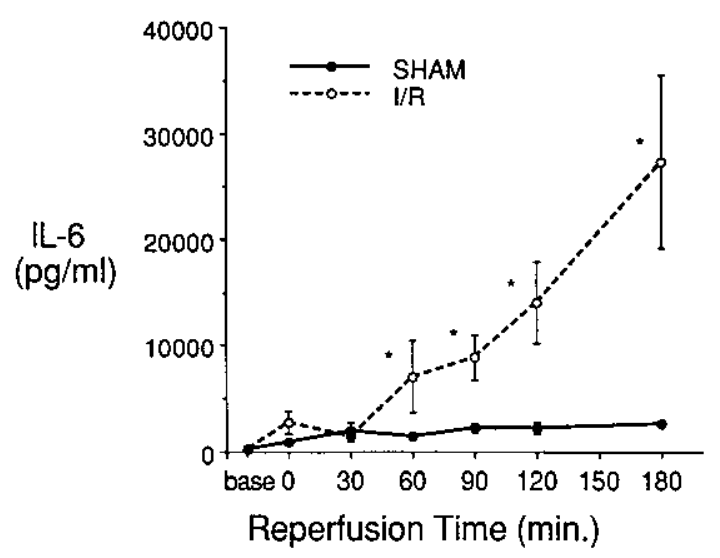

FIG. 2. Plasma levels of IL-6 following hepatic ischemia/reperfusion. Time 0 represents the values at $2 \mathrm{hr}$ of ischemia prior to reperfusion. All other time points represent the time following reperfusion. Values $=$ means $\pm \mathrm{SEM}, n=5 \mathrm{I} / \mathrm{R}$ rats, $n=4$ sham rats. ${ }^{*} P \leqslant 0.05$ compared to sham values at similar time points.

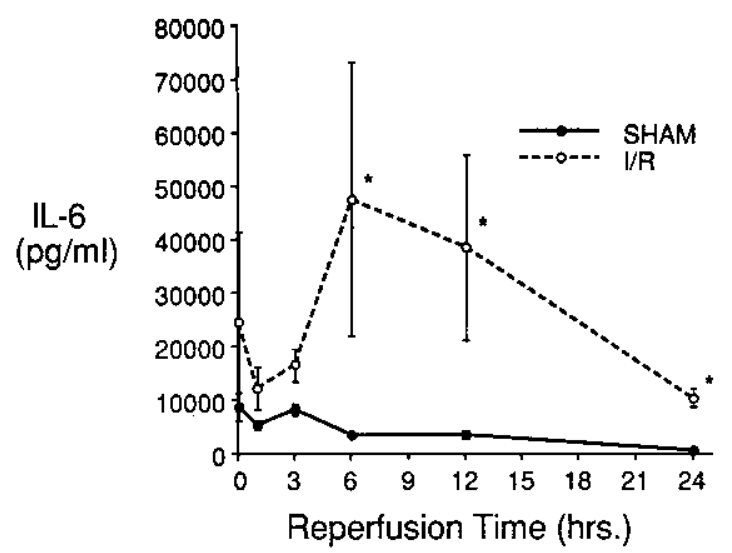

FIG. 3. Kinetics of plasma IL-6 over $24 \mathrm{hr}$ of reperfusion following hepatic ischemia. Time 0 represents the values at $2 \mathrm{hr}$ of ischemia prior to reperfusion. All other time points represent the time following reperfusion. Values $=$ means $\pm \mathrm{SEM} ; n=6 \mathrm{I} / \mathrm{R}$ rats, $n=4$ sham rats. ${ }^{*} P \leqslant 0.05$ compared to sham values at similar time points.

we noted a large variance in our data collected over the $24 \mathrm{hr}$ of reperfusion, the results indicate that maximal levels of plasma IL-6 were detected 6 to $12 \mathrm{hr}$ of reperfusion. Low, but detectable, IL-6 was measured in the plasma of sham-operated controls over this time course. There appears to be a discrepancy between the plasma IL-6 data obtained in the 3- and 24-hr kinetic experiments, specifically when examining values obtained at the end of the ischemic interval prior to reperfusion. The plasma IL- 6 values at the end of the 2 -hr ischemic inter$\mathrm{val}$ (Time 0) are $2740 \pm 1040 \mathrm{pg} / \mathrm{ml}$ and $24,600 \pm 16,700$ $\mathrm{pg} / \mathrm{ml}$ for the 3- and $24-\mathrm{hr}$ experiments, respectively. Although the nature of the response appears to be similar, clearly the data obtained from the $24-\mathrm{hr}$ experiment is of greater magnitude than that of the $3-\mathrm{hr}$ kinetic study. The IL-6 values measured in the sham animals are similarly elevated in the $24-\mathrm{hr}$ experiment at Time 0 as compared to the 3 -hr kinetic study. Plasma TNF bioactivity measured in the 24-hr experiment (data not shown), was also greater than that for similar time points in the 3 -hr study (for example, TNF at $1 \mathrm{hr}$ of reperfusion $=604 \pm 114 \mathrm{pg} / \mathrm{ml}$ and $59 \pm 12 \mathrm{pg} / \mathrm{ml}$ in the 24- and 3-hr studies, respectively). The apparent increase may be a reflection of variability with bioassays from experiment to experiment, relatively greater hepatocellular injury as a result of ischemia, or an enhancement of other stimuli responsible for the upregulation of a cytokine response for the 24-hr study compared to the 3 -hr experiment. Although we noted this variability in plasma IL-6 measured at early time points, the data in Figs. 2, 3, and 4, from independent experiments, show more consistent levels of IL-6 at 3 through $24 \mathrm{hr}$ of reperfusion.

With the evidence that TNF is produced in this model prior to IL-6, and because TNF has been shown to induce IL-6 [8], we tried to determine their relationship by inhibiting TNF with our polyclonal anti-TNF anti- 


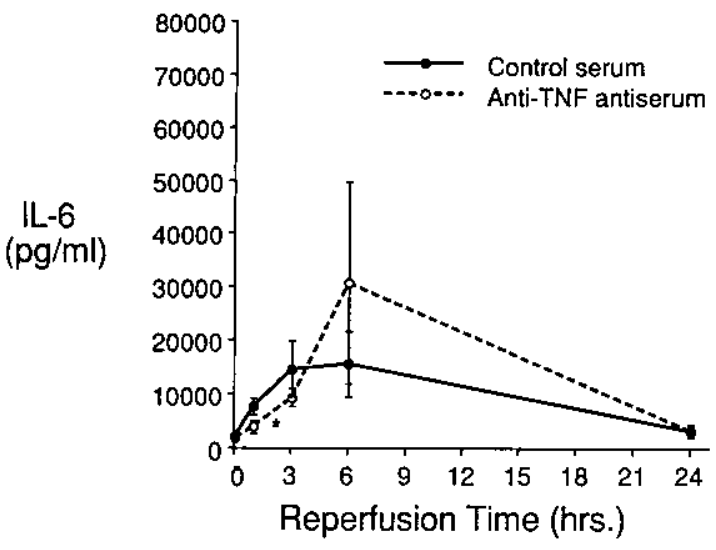

FIG. 4. Effect of TNF immunoneutralization on IL-6 levels following hepatic ischemia/reperfusion. Animals received intravenous injections of either anti-TNF antiserum or control serum prior to undergoing hepatic ischemia/reperfusion. Values = means $\pm \mathrm{SEM} ; n=5$ anti-TNF-treated rats, $n=4$ control serum-treated rats. ${ }^{*} P \leqslant 0.05$ control serum vs anti-TNF serum only at the 1 -hr time point.

serum. Pretreatment with anti-TNF antiserum resulted in significant lowering of IL-6 levels but only at the 1-hr time point (Fig. 4). Differences in values between the groups were not significantly different at other time points measured. Antibody pretreatment effectively inhibited plasma TNF bioactivity (data not shown), confirming the efficacy of the antiserum.

Since anti-TNF treatment did not decrease IL-6, and IL- 6 is a major inducer of the hepatic acute phase response, we evaluated if anti-TNF would affect acute phase proteins. The change in serum protein electrophoretic patterns for the groups of animals tested are shown in Figs. 5 and 6. Comparison of values following reperfusion to the preischemic value within each group revealed a significant elevation of the macroglobulin/albumin ratio in all four groups suggestive of an acute phase response. Interestingly, the sham-operated animal values appear higher than those of the I/R group, but are signifi-

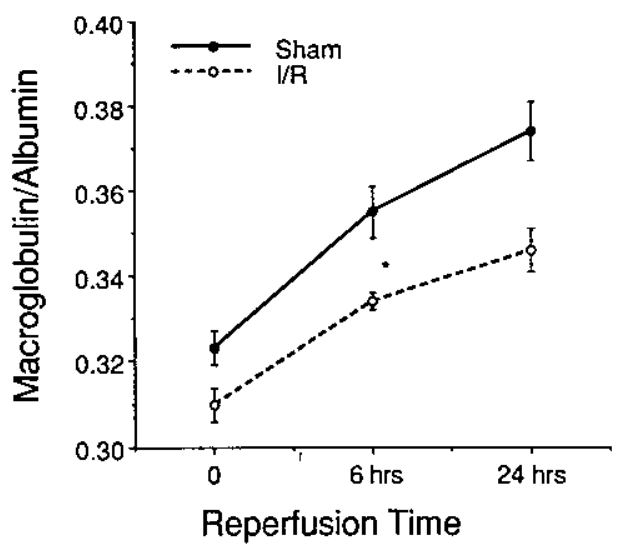

FIG. 5. Serum macroglobulin $\left(\alpha_{1}+\alpha_{2}\right)$ to albumin ratios as a function of hepatic reperfusion time. Values = means \pm SEM; $n=7$ I/R rats, $n=9$ sham rats. ${ }^{*} P \leqslant 0.05$ compared to sham values at the 6-hr time point.

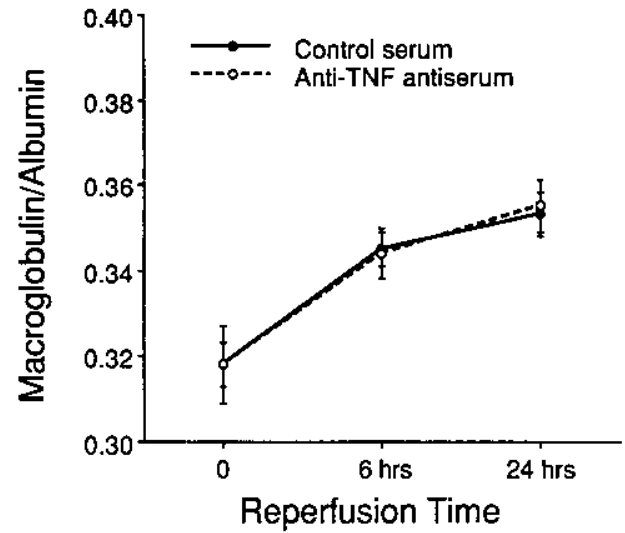

FIG. 6. The effect of TNF immunoneutralization on serum macroglobulin to albumin ratios following hepatic ischemia/reperfusion. Animals received intravenous injections of either anti-TNF anti. serum or control serum prior to undergoing hepatic ischemia/reperfusion. Values $=$ means $\pm \mathrm{SEM} ; n=5$ anti-TNF-treated rats, $n=4$ control serum-treated rats.

cantly higher at only the 6 -hr time point (Fig. 5). Comparison of groups pretreated with anti-TNF antiserum or control serum revealed no significant differences, with almost identical values (Fig. 6).

\section{DISCUSSION}

Hepatic ischemia is a common problem in clinical practice, occurring as a sequelae to hemorrhage, in association with sepsis or in association with various types of liver surgery, including most dramatically liver transplantation. As with other organs, it is increasingly recognized that the events occurring after reperfusion of the ischemic liver contribute significantly to the aggregate liver injury. This recognition is important because the postischemic events, collectively referred to as "reperfusion injury," may be more amenable to treatment than is the ischemia.

Many of the experimental studies involving hepatic ischemia/reperfusion injury have utilized the model of rat lobar ischemia used in this communication. In this model, the left and median lobes of the rat liver, which represent $70 \%$ of the mass of the liver, undergo $2 \mathrm{hr}$ of ischemia, via clip application to the portal vein, hepatic artery, and bile duct of the left and median lobes. An attractive feature of this model is that portal flow through the right lobe is unaltered during the period of clip occlusion. Passive venous congestion of the intestines is avoided, providing for hemodynamic stability and diminished opportunity for bacterial translocation and endotoxemia. In a previous study we examined the portal blood for evidence of endotoxin during clip occlusion and found none [6], a critical issue since mononuclear cells are exquisitely sensitive to picogram concentrations of endotoxin with regard to TNF and other cytokine production [14]. An additional important feature of the current model is that the animals were not heparinized, in order to avoid the significant intraabdominal 
hemorrhage noted after clip occlusion when heparin was administered in previous studies. This variable could significantly influence results since we have noted considerable variation in the degree of hemorrhage from animal to animal. Relevant to the present work, Chaudry et al. have demonstrated that hemorrhage is associated with significant elevation of plasma IL-6 in rats [15].

Previous studies involving rat lobar hepatic ischemia/ reperfusion injury have documented the important contribution of oxidant injury during reperfusion. Antioxidant therapy, including desferol, an iron chelator [16], long-acting superoxide dismutase [17], or $\alpha$-tocopherol [18], significantly protected against hepatocyte damage manifested by transaminase release. In our previous studies of hepatic reperfusion injury, we noted that biologically active TNF appeared in suprahepatic vena caval blood shortly following reperfusion [6]. Preadministration of antibody to TNF significantly protected against reperfusion injury, indicating that hepatic exposure to the cytokine TNF is an important mechanism of reperfusion injury in addition to mechanisms involving oxidant formation. Although the source of the systemic TNF has not as yet been precisely identified, as a vast reservoir of fixed tissue macrophages, the ischemic Kupffer cells are likely candidates since the monocytemacrophage is a potent producer of this cytokine.

Many in vivo models examining the role of cytokines in pathophysiology have demonstrated that a given inflammatory stimulus resuits not in the generation of a single cytokine, but rather a complex cascade of cytokine release [19-23]. In accordance with this, our demonstration of circulating TNF following partial hepatic ischemia/reperfusion has led us to examine the production of other cytokines, in particular IL- 6 . We chose to study IL- 6 because TNF has been demonstrated to be an important stimulus for IL-6 production [8], and IL-6 is the predominant stimulus for the hepatic acute phase response, an important nonspecific host defense mechanism [4]. We hypothesized that since TNF appeared to be generated at early time points following ischemia/reperfusion, the appearance of IL- 6 would follow sequentially. Further, if the ischemia/reperfusion insult resulted in detectable IL-6 levels, we predicted that detectable changes in acute phase proteins would be observed, reflected in the serum macroglobulin to albumin ratio. Information about IL-6 in this context could lead to effective strategies aimed at protecting against the sequelae of ischemia/reperfusion.

Our findings confirm previous observations $[6,7]$ that reperfusion of the ischemic rat liver leads to the very rapid appearance of systemic TNF bioactivity. In addition, these results demonstrate a dramatic but later peak of systemic IL- 6 bioactivity. Our data show that the sequential appearance of TNF followed by IL-6 observed in endotoxin shock models [20] is also found after hepatic ischemia/reperfusion. This strong temporal relationship might suggest cause and effect, but prior admin- istration of anti-TNF antibody, in a dose regimen that has consistently protected against liver injury in other experiments, failed to suppress IL-6 activity except at the earliest time point. At other time points following ischemia/reperfusion, there was an enhanced IL-6 response after anti-TNF antibody pretreatment. The early stimulation of IL-6 production may in fact be attributable to TNF release, but subsequent stimulation of IL-6 may result from interleukin 1 (IL-1). As mentioned above, due to the complex nature of an inflammatory response, IL-1, also a product of monocyte-macrophages and a potent stimulus for IL-6 production [8], is likely to be generated following ischemia/reperfusion. This would explain the failure of anti-TNF antibody pretreatment to alter the IL-6 response, as the anti-TNF antibody used in our experiment displays no cross-reactivity for IL-1. Recently it was found that administration of IL-1 receptor antagonist or a monoclonal antibody to the IL-1 receptor effectively inhibited the acute phase response seen after LPS administration in mice [21]. Our results are in contrast to those obtained when the stimulus for TNF release was gram-negative bacteria injection into baboons, in which it was seen that anti-TNF antibody pretreatment effectively inhibited a subsequent IL-6 response [22]. This discrepancy may pertain to alternative pathways of TNF and IL-6 stimulation in these two models (our I/ $\mathrm{R}$ model has been demonstrated to be endotoxin independent) and the cells responsible for cytokine synthesis. Pretreatment of rats with either polyclonal or monoclonal anti-TNF antibodies was shown to blunt but not completely prevent IL-6 production after LPS injection [23, 24], and similarly, anti-TNF antibodies did not prevent the IL-6 response in LPS-stimulated human whole blood [25].

Evidence for an acute phase response was seen following ischemia/reperfusion but somewhat surprisingly this change was not appreciably different from that seen in sham-operated animals not undergoing ischemia/reperfusion. We believe that the acute phase response observed in sham-operated animals is the result of low but important baseline levels of IL-6 activity induced as the result of midline laparotomy with anesthesia. Elevated IL- 6 has been noted in sham-operated animals independent of TNF activity [15]. Similarly, in humans, Shenkin et al. [26] reported that surgical procedures not associated with significant hemorrhage produced elevations of IL- 6 but not TNF. The apparent sensitivity of the acute phase response to low levels of IL-6 most probably accounts for the indistinguishable profiles of macroglobulin/albumin in animals with high IL-6 levels following ischemic/reperfusion, relative to sham-operated animals.

The finding that anti-TNF antibody pretreatment did not block IL-6 activity except at the earliest time point might actually help to explain the protective effect of anti-TNF antibody treatment noted previously in this model. In addition to a direct anti-TNF effect, the unin- 
hibited IL-6 response might act to limit ongoing TNF production, since it has been shown that IL-6 suppresses IL- $1 \beta$ and TNF production by peripheral blood mononuclear cells in response to LPS or PHA in vitro [27], and when given to mice in vivo [28]. In vivo intratracheal injection of IL- 6 significantly reduced TNF- $\alpha$ production in bronchoalveolar lavage fluid of LPS-treated rats [29]. Finally, it is clear in the model used in this study that anti-TNF antibody does not act to abrogate the induction of acute phase proteins either by ischemia/reperfusion or sham laparotomy, thus preserving whatever functional protection is provided by varied components of the acute phase response.

\section{REFERENCES}

1. Kashiwamura, S., Nakajima, K., Koyama K., Iwamatsu, K., Tsunasawa, S., Sakiyama, F., Matsui, H., Takahara, Y., Taniguchii, T., and Kishimoto, T. Complementing DNA for a novel human interleukin (BSF-2) that induces B-lymphocytes to produce immunoglobulins. Nature (London) 324: 73, 1986.

2. Ikebuchi, K., Wong, G., Clark, S., Ihle, J., Hirai, Y., and Ogawa, M. Interleukin- 6 enhancement of interleukin 3 dependent proliferation of multi-potential hemopoietic progenitors. Proc. Natl. Acad. Sci. 84: 9035, 1987.

3. Taka, Y., Wong, G., Clark, S., Buralcoff, S., and Herrmann, S. B cell stimulating factor-2 is involved in the differentiation of cytotoxic T lymphocytes. J. Immunol. 140: 508, 1988.

4. Gauldie, J., Richards, C., Hapaish, D., Lansdorp, P., and Baumann, H. Interferon B-2/B-cell stimulating factor type 2 share identity with monocyte derived haptocyte stimulating factor and regulates the major acute phase protein response in liver cells. Proc. Natl. Acad. Sci. 84: 7251, 1987.

5. Koj, A. Biological functions of acute phase proteins and the cytokines involved in their-induced synthesis. In W. Reuter and $\mathrm{H}$. Popper (Eds.), Modulation of Liver Cell Expression. Falk Symposium No. 43. Lancaster: MTP Press. 1986, Pp. 331-342.

6. Colletti, L. M., Remick, D. G., Burtch, G. D., Kunkel, S. L., Strieter, R. M., and Campbell, D. A., Jr. Role of tumor necrosis factor- $\alpha$ in the pathophysiologic alterations after hepatic ischemia/reperfusion in the rat. J. Clin. Invest. 85: 1936, 1990.

7. Colletti, L. M., Burtch, G. D., Remick, D. G., Kunkel, S. L., Strieter, R. M., Guice, K. S., Oldham, K. T., and Campbell, D. A. Production of tumor necrosis factor alpha and the development of a pulmonary capillary injury following hepatic ischemia/reperfusion. Transplantation 49(2): 268, 1990.

8. Jirik, F., Podon, T., Hronoj, T., Kishimoto, T., Loskutoff, D., Carson, D., and Latz, M. Bacterial lipopolysaccharide and inflammatory mediators augment IL-6 secretion by human endothelial cells. J. Immunol. 142: 144, 1989.

9. Hayashi, H., Chaudry, I. H., Clemens, M. G., and Baue, A. E. Hepatic ischemia models for determining the effects of ATP$\mathrm{MgCl}_{2}$ treatment. J. Surg. Res. 40: 167, 1986.

10. Remick, D. G., Strieter, R. M., Eskandari, M. K., Nguyen D. T., Genord, M. A., Raiford, C. L., and Kunkel, S. L. Role of tumor necrosis factor alpha in lipopolysaccharide-induced pathologic alterations. Am. J. Path. 136: 49, 1990.

11. Warren, J. S., Yabroff, K. R., Remick, D. G., Chensue, S. W., Kunkel, S. L., and Kunkel, R. G., Johnson, K. J., and Ward, P. A. Tumor necrosis factor participates in the pathogenesis of acute immune complex alveolitis in the rat. J. Clin. Invest. 84: 1873, 1989.
12. Eskandari, M. K., Nguyen, D. T., Kunkel, S. L., and Remick, D. G. WEHI 164 subclone 13 assay for TNF: Sensitivity, specificity and reliability. Immunol. Invest. 19(1): 69, 1990.

13. Aarden, L. A., deGroot, E. R., Shaap, O. L., and Lansdorp, P. M. Production of hybridoma growth factor by human monocytes. Eur. J. Immunol. 17: 1411, 1987.

14. Rock, C., and Lowry, S. Tumor necrosis factor- $\alpha$. J. Surg. Res. 51: 434, 1991 .

15. Ayala, A., Wang, P., Ba, Z., Perrin, M., Ertel, W., Chardry, I. Differential alterations in plasma IL-6 and TNF levels after trauma and hemorrhage. Am. J. Physiol. 260: R167, 1991.

16. Omar, R., Nomikos, I., Piccorelli, G., Savino, J., and Agarwal, N. Prevention of post ischemic lipid peroxidation and liver cell injury by iron chelation. Gut 30: 510, 1989.

17. Romani, F., Vertemati, M., Frang, M., Aseni, P., Monti, R., Codeghini, A., and Belli, L. Effect of superoxide dismutase on liver ischemia-reperfusion injury in rat: A biochemical monitoring. Eur. Surg. Res. 20: 335, 1989.

18. Marubayashi, S., Dohi, K., Sugino, K., and Kawasaki, T. The protective effect of administered alpha-tocopherol against hepatic damage caused by ischemia-reperfusion or endotoxemia. Ann. N.Y. Acad. Sci. 570: 208, 1989.

19. Creasey, A. A., Stevens, P., Kenney, J., Allison, A. C., Warren, K., Catlett, R., Hinshaw, L., and Taylor, F. B., Jr. Endotoxin and cytokine profile in plasma of baboons challenged with lethal and sublethal Escherichia coli. Circ. Shock 33: 84, 1991.

20. Waage, A., Brandtzaeg, P., Haltensen, A., Kierulf, P., and Espevik, T. The complex pattern of cytokines in serum from patients with meningococcal septic shock. J. Exp. Med. 169: 333, 1989.

21. McIntyre, K. W., Stepan, G. J., and Kolinsky, D. K. Inhibiting of IL-1 binding and bioactivity in vitro and modulation of acute inflammation in vivo by IL-1 receptor antagonists and anti-IL-1 receptor monoclonal antibody. J. Exp. Med. 173: 931, 1991.

22. Fong, Y., Tracey, K., Modawer, L., Hesse, D., Manoque, K., Kenney, J., Lee, A., Juo, G., Allison, A., Lowry, S., and Cerami, A. Antibodies to cachectin/tumor necrosis factor reduce interleukin $1 \beta$ and interleukin 6 appearance during lethal bacteremia. $J$. Exp. Med. 170: 1627, 1989.

23. Shalaby, M. R., Waage, A., Aarden, L., and Espevik, T. Endotoxin tumor necrosis factor $\alpha$ and interleukin. 1 induce interleukin 6 production in vivo. Clin. Immunol. Immunopathol. 53: 488 , 1989.

24. Sharma, R. J., Macallan, D. C., Sedgwick, P., Remick, D. G., and Griffin, G. E. Kinetics of endotoxin induced acute phase protein expression in liver and its modulation by monoclonal antibody to TNF- $\alpha$ in the rat. Am. J. Physiol. 262: R786, 1992.

25. DeForge, L. E., Kenney, J. S., Jones, M. L., Warren, J. S., and Remick, D. G. Biphasic production of IL-8 in lipopolysaccharide (LPS)-stimulated human whole blood. Separation of LPS- and cytokine-stimulated components using anti-tumor necrosis factor and anti-IL-1 antibodies. J. Immunol. 148: 2133, 1992.

26. Shenkin, A., Fraser, D., Series, J., Winstanely, A., McCartney, H., Burns, J., and Van Damme, J. The serum interleukin- 6 response to elective surgery. Lymphokine Res. 8: 123, 1989.

27. Schindler, R., Mancilla, J., Endres, S., Ghorbani, R., Clark, S., and Dinarello, $\mathrm{C}$. Correlations and interactions in the production of interleukin-6, IL-1 and tumor necrosis factor in human blood mononuclear cells: IL-6 suppresses IL-1 and TNF. Blood 75: 40, 1990.

28. Aderka, D., Le, J., and Vilcek, J. IL-6 inhibits lipopolysacharideinduced tumor necrosis factor production in cultured human monocytes U937 cells and in mice. J. Immunol. 143: 3517, 1989.

29. Ulich, T. R., Yin, S., Guo, K., Yi, E., Remick, D., and del Castillo, J. Intratracheal injecting endotoxin and cytokines. II. Interleukin 6 and transforming growth factor beta inhibit acute inflammation. Am. J. Pathol. 138: 1097, 1991. 